\title{
The Great Gatsby e o personagem Nick Carraway como ser de fronteira
}

\author{
The Great Gatsby and the character Nick Carraway as \\ a frontier being
}

\begin{abstract}
Ricelly Jáder Bezerra da Silva* ricellyjaderbezerra@gmail.com Universidade Federal do Ceará
\end{abstract}

RESUMO: The Great Gatsby, de F. Scott Fitzgerald, publicado primeiramente em 1925, é um dos mais importantes romances do cânone literário estadunidense. Em seu texto, Fitzgerald apresenta relações socioculturais da década de 1920, nos EUA, período conhecido como a "era do jazz", em que ocorreram mudanças socioculturais significativas. A narrativa é contada através da perspectiva do personagem Nick Carraway. Assim, o objetivo deste artigo é analisar a posição do referido personagem como um ser de fronteira, pois Carraway transita entre diferentes ambientes sociais sem pertencer a nenhum deles. Dessa forma, partimos da hipótese de que, como ser de fronteira, o personagem revela problemas socioculturais de sua época. Como base teórica, recorremos aos estudos de semiótica da cultura de Lótman (1996), e à discussão de Bakhtin (2011) acerca da personagem literária. O resultado indica que é através da posição fronteiriça do personagem que problemas sociais, morais e culturais são revelados ao leitor.

PALAVRAS-CHAVE: Literatura. Semiótica. Personagem. Ser de fronteira. Ressignificação.

ABSTRACT: The Great Gatsby, by F. Scott Fitzgerald, first published in 1925, is one of the most important novels in the American literary canon. In his text, Fitzgerald presents sociocultural relations of the 1920s in the United States, period also known as "the Jazz Age", in which significant sociocultural changes occurred. The narrative is told from the perspective of character Nick Carraway. Therefore, this article aims at analyzing the position of the character as a frontier being, once Carraway attends different social settings, but does not belong to any of them. Hence, our hypothesis is that as a frontier being, the character reveals sociocultural problems of his time. As to the theoretical basis of this study, we resorted to Lótman's (1996) studies about the semiotics of culture and to Bakhtin's (2011) discussion on literary character. The result indicates that it is through the frontier position of the character that social, moral, and cultural problems are revealed to the reader.

KEYWORDS: Literature. Semiotics. Character. Frontier Being. Resignification.

\footnotetext{
Doutorando em Letras pelo Programa de Pós-Graduação em Letras da Universidade Federal do Ceará (UFC), e bolsista FUNCAP. Este trabalho foi realizado com apoio da Fundação Cearense de Apoio ao Desenvolvimento Científico e Tecnológico - FUNCAP.
} 


\section{Introdução}

Francis Scott Fitzgerald nasceu em St. Paul, Minnesota, em 24 de setembro de 1896. O autor frequentou a Universidade de Princeton, mas não concluiu seus estudos; assim, decidiu se alistar no exército em 1917. Ao final da Primeira Guerra Mundial, Fitzgerald retornou à sua cidade de origem e trabalhou em seu primeiro romance, This Side of Paradise, publicado no ano de 1920. A esse trabalho, seguiram-se outros, dos quais se destacam: The Great Gatsby, em 1925, Tender is the Night, em 1934, e The Last Tycoon ${ }^{1}$, em 1940. Além de romances, o autor também produziu vários contos e, dentre eles, The Curious Case of Benjamin Button ${ }^{2}$, publicado em 1922, sendo um dos mais conhecidos.

Neste trabalho, o romance The Great Gatsby constitui nosso corpus. Essa obra apresenta os principais elementos da sociedade estadunidense dos anos 20. O autor retrata a cultura hedonista da classe abastada, mas também revela incongruências em suas relações sociais e na maneira como as personagens percebem sua realidade. Apesar de não ser o personagem principal, toda a história é contada através do ponto de vista de Nick Carraway, que, a despeito de não fazer parte da elite, constrói uma forte amizade com Gatsby, o herói do romance. Nossa hipótese é a de que, ao relatar os eventos que ocorrem no romance de uma posição fronteiriça, a voz narrativa também revela representações de uma cultura, ou seja, uma semiosfera (LÓTMAN, 1996) - como discutiremos em seguida - e, de tal maneira, age como elo entre a obra e o leitor, suscitando reflexões e ressignificações.

Como base teórica principal, recorremos aos estudos de semiótica da cultura, de Lótman (1996), e aos estudos a respeito da personagem de ficção, de Bakhtin (2011). Além disso, em nossa análise, selecionamos e apresentamos alguns fragmentos do romance. O trabalho está dividido em quatro seções, sendo que, primeiramente, apresentamos o contexto de produção da obra, bem como discutimos os conceitos de semiosfera e de sujeito de fronteira. Em seguida, expomos nossas considerações sobre a

\footnotetext{
${ }^{1}$ Este romance constitui-se numa obra inacabada, pois o autor faleceu enquanto o escrevia.

2 O conto foi publicado na coletânea Tales of the Jazz Age.
} 
personagem de ficção. Logo após, procedemos com a análise e, finalmente, apresentamos as considerações finais.

\section{Uma semiosfera dos anos 20: the roaring twenties e o sujeito de fronteira}

A década de 1920 foi um período de consolidação de grandes transformações políticas, econômicas e socioculturais em várias partes do mundo, sobretudo, devido a mudanças provocadas em decorrência da Primeira Guerra Mundial. Nesse contexto, os Estados Unidos se tornaram a primeira grande potência econômica do século XX. Como resultado de sua posição hegemônica, o país teve seu primeiro grande boom econômico, cristalizando valores associados ao American Dream. Assim, a noção de uma nação igualitária, próspera, livre e com muitas oportunidades para qualquer sujeito disposto a trabalhar e a enriquecer foi reforçada.

De tal modo, várias transformações ocorreram na sociedade estadunidense. Como exemplo, podemos citar o maior fluxo de investimentos na bolsa de valores do período, a reconfiguração do processo de urbanização das cidades americanas com a construção de grandes arranha-céus e o crescimento da liberdade sexual feminina. Além disso, o jazz - presença constante no universo literário de Fitzgerald - tornou-se a música de festas opulentas regadas à bebida alcoólica. Ao tratar a esse respeito, Kirk Curnutt (2007) resume o contexto da década de 1920 ao afirmar que o período tende a ser lembrado como uma época de indulgência e impulsos inconsequentes, em que a prosperidade parecia infinita e a irresponsabilidade era um direito adquirido desde o nascimento.

No entanto, essas mudanças também tiveram um viés conservador. 0 governo estadunidense, por meio da aprovação da Lei Seca ${ }^{3}$ em 1920, instaurou a proibição do consumo de álcool. Em decorrência dessa ação, a bebida alcoólica passou a ser produzida de maneira ilegal, contrabandeada e consumida em estabelecimentos clandestinos, com suporte financeiro da classe abastada, uma vez que essa classe constituía um dos principais

\footnotetext{
${ }^{3}$ Também conhecida como Prohibition, essa lei proibia a fabricação, transporte e consumo de bebidas alcóolicas em todo o país.
} 
consumidores de tal mercadoria. Em suma, a década de 20 do século $X X$, especialmente nos EUA, passou a ser conhecida como The roaring twenties ${ }^{4}$, isto é, os anos de riqueza, luxo e desenvolvimento econômico e urbano que antecederam a quebra da bolsa de Nova York em 1929.

Nesse contexto, o escritor F. Scott Fitzgerald produziu um dos principais livros da literatura estadunidense, o romance The Great Gatsby, publicado primeiramente em 1925. A obra do autor, considerada uma tragédia contemporânea, reflete as características mais relevantes dessa década (HIGH, 2000) no que diz respeito ao zeitgeist da época, apresentando elementos históricos, sociais e culturais pela voz narrativa de um dos principais personagens, Nick Carraway. Em outras palavras, The Great Gatsby apresenta, ao leitor contemporâneo, a imagem de uma semiosfera dos anos 20 , o que suscita reflexão a respeito de valores da época e de valores socioculturais contemporâneos também.

Semiosfera é um termo cunhado pelo professor e pesquisador luri Lótman (1996), da escola de Tártu-Moscou ${ }^{5}$, ao investigar as relações culturais nas sociedades. Para Lótman (1996), a cultura de uma sociedade é estruturada de maneira que existam elementos reguladores e dinâmicos a partir de um núcleo, ou seja, elementos que geram significados, transformando-se e se renovando ao longo do tempo. Ao abordar o assunto, o autor declara que:

O universo semiótico pode ser considerado como um conjunto de diferentes textos e linguagens fechadas em relação uns aos outros. Então, todo o edifício terá a aparência de ser feito de tijolos diferentes. No entanto, a abordagem oposta parece mais frutífera: todo espaço semiótico pode ser considerado como um mecanismo único (se não como um organismo) (LÓTMAN, 1996, p. 12) ${ }^{6}$.

\footnotetext{
${ }^{4}$ Em português essa expressão é comumente traduzida como "os loucos anos 20 ".

${ }^{5}$ Refere-se aos estudos de semiótica russa, desenvolvidos por um grupo de pesquisadores e professores, que foram estabelecidos nas universidades das cidades de Tartu e Moscou. Os membros desse grupo produziam seus estudos e divulgavam entre si em encontros anuais que duraram até meado da década de 1980. Um dos fundadores foi luri Lótman.

${ }^{6} \mathrm{~N}$. do A.: Todas as traduções sem referência no português são minhas. No texto em espanhol: "Se puede considerar el universo semiótico como un conjunto de distintos textos y de lenguajes cerrados unos con respecto a los otros. Entonces todo el edificio tendrá el aspecto de estar constituido de distintos ladrillitos. Sin embargo, parece más fructífero el acercamiento contrario: todo el espacio semiótico puede ser considerado como un mecanismo único (si no como un organismo)".
} 
De tal modo, a semiótica da cultura tem como objetivo o estudo das manifestações culturais, considerando-as constituídas por meio de linguagens e diálogos entre seus diversos elementos verbais e não verbais.

Para Lótman (1996), os elementos que compõem uma cultura, isto é, a memória coletiva, os valores, comportamentos, entre outros fatores, estruturam-se por meio de e a partir da linguagem, de relações dialógicas e complexas que devem ser compreendidas em seu todo e não separadamente. Portanto, apenas considerando a manifestação da cultura em um dado contexto de maneira ampla se pode compreender os discursos e os significados gerados por esse dialogismo. Além disso, a cultura não é algo estático, pois, por sua natureza dialógica, novos significados são gerados - daí a noção de se tratar de um organismo vivo.

Dessa forma, certa cultura estabelecida possui um centro, um signo central cuja função principal é sustentar, promover a manutenção de valores, conceitos, discursos que existem em um determinado sistema sociocultural. Não obstante, por existir um signo regulador, há também, como desdobramento, a criação de periferias, ou de fronteiras (LÓTMAN, 1996). Dessa forma, é a partir das fronteiras, do que está entre um sistema cultural e outro, que novos paradigmas, novos significados e transformações podem ocorrer. Portanto, se considerarmos a década de 1920, é correto afirmar que há uma semiosfera constituída, uma vez que existe uma estrutura social, cultural e econômica que sustenta os comportamentos e as leituras de mundo de um grupo social dominante naquele contexto, ao passo que exclui outros grupos sociais. Na obra de Fitzgerald, podemos citar, como referência a essa dinâmica, as relações entre personagens ricos, como Tom Buchanan e outros pobres, como o mecânico Wilson.

Outro elemento importante discutido por Lótman (1996) é o conceito de sujeito de fronteira. Trata-se do sujeito que não pertence ao centro, cuja posição lhe permite ressignificar os signos de uma semiosfera. De acordo com o autor, há duas categorias de sujeitos de fronteira. A primeira é constituída a partir da visão do centro de uma cultura, isto é, o sujeito de fronteira é definido aa partir das concepções de um grupo sociocultural dominante. Como exemplo, podem-se citar narrativas históricas nas quais os habitantes autóctones da 
América são considerados como seres exóticos pelos colonos europeus e, por isso, não humanos.

A segunda categoria de sujeito de fronteira é constituída a partir da posição do próprio sujeito que não habita o centro de um sistema cultural. Nesse sentido, a posição marginal ou idiossincrática desse sujeito permite uma ressignificação mais efetiva de elementos de certa cultura (LÓTMAN, 1996). É nesse sentido que entendemos a posição do personagem Nick Carraway, da obra The Great Gatsby (2016). Sua posição periférica, uma vez que ele não pertence à classe rica, e sua função como narrador no referido romance apresentam, ao leitor, uma noção da cultura da classe abastada nos EUA durante aquele período, ao mesmo tempo em que geram identificação com o leitor.

Portanto, na obra de Fitzgerald, o leitor tem acesso a uma semiosfera através da voz narrativa de um sujeito de fronteira. O narrador do romance de Fitzgerald é um estranho, um "estrangeiro", no sentido de alguém que percebe com estranheza, que não naturaliza e, dessa maneira, acaba por possibilitar releituras, ressignificações de um dado contexto de modo a suscitar reflexões acerca de valores socioculturais de seu tempo, mas que reverberam na contemporaneidade.

De acordo com Lótman (1996), o papel da fronteira é o de um catalizador de transformação e de tradução entre diferentes sistemas ou semiosferas. É na fronteira onde ocorrem filtragens que resultam em novos paradigmas, conceitos, valores e comportamentos. Nesse sentido, filtragem se refere às bordas de um sistema sígnico. As fronteiras, para Lótman (1996), são separadas por elementos abstratos - assim como as células vivas, cujas bordas estão protegidas por membranas que filtram os elementos internos $\mathrm{e}$ externos ao núcleo. Ao tratar do assunto, o autor declara que:

Assim como na matemática, chama-se de fronteira um conjunto de pontos pertencentes simultaneamente ao espaço interior e ao espaço exterior, a fronteira semiótica é a soma dos tradutores bilíngues - "filtros" - através dos quais um texto se traduz em outra linguagem (ou linguagens) que está fora de uma dada semiosfera (LÓTMAN, 1996, P. 12) ${ }^{7}$.

\footnotetext{
${ }^{7}$ No texto em espanhol: "Así como en la matemática se llama frontera a un conjunto de puntos perteneciente simultáneamente al espacio interior $\mathrm{y}$ al espacio exterior, la frontera semiótica es
} 
Trata-se, assim, de uma fronteira abstrata. Esse processo de tradução por meio da filtragem ocorre através da interação entre os elementos que estão aquém e além da fronteira, isto é, dentro e fora de uma semiosfera, bem como pelo sujeito que habita nesse local. Nesse sentido, há uma relação dialógica constante nos espaços fronteiriços e, nesse processo dialógico, elementos são filtrados e penetram numa semiosfera, assim, passando por um tipo de tradução e, como resultado desse processo semiótico, ocorrem transformações e ressignificações.

\section{A personagem literária como ser estético-crítico}

O enredo de um conto, de um romance, de um filme, ou de qualquer outra forma de arte que apresente estrutura narrativa, centra-se em uma ou mais personagens, quer se trate de objetos, de pessoas, de animais e/ou de plantas (ROSENFELD, 2011). E, mesmo que ela não apareça diretamente, a voz narrativa poderá ocupar tal função. Assim, é por meio de tais entes fictícios que o leitor interage com o texto e, nessa interação, a história ganha dinamicidade e ideias são construídas.

Para Mikhail Bakhtin (2011), a personagem é resultado de uma atividade reflexiva e estética. Portanto, o autor de obra literária vislumbra todos os aspectos de sua criação, ao passo que, ao se basear em outra pessoa ou em si mesmo, o escritor não poderia abarcar o todo, uma vez que o ser humano não pode ter acesso direto aos pensamentos e aos sentimentos do outro ou conhecer-se a si mesmo em sua totalidade. Assim, não seria possível para o autor escrever sobre si ou sobre o outro de forma tão completa como o faz com a personagem de ficção. Nesse sentido, ao escrever a respeito de si ou acerca de alguém, o autor, inevitavelmente, cria aspectos, traços psicológicos e físicos, em suma, cria e se desvia do "real". Desse modo, o escritor pode usar referências externas, de acordo com o conceito da mimeses aristotélica. Mas, ao estruturar sua personagem, ele entrevê toda sua consciência, todo o seu ser; não de seu próprio ponto de vista, porém, do ponto de vista da

la suma de los traductores-«filtros» bilingües pasando a través de los cuales un texto se traduce a otro lenguaje (o lenguajes) que se halla fuera de la semiosfera dada". 
personagem, e esta, assim, ganha identidade. Ao discutir acerca do processo de elaboração da personagem, Bakhtin afirma que:

As personagens criadas se desligam do processo que as criou e começam a levar uma vida autônoma no mundo, e de igual maneira o mesmo se dá com seu real criador-autor. É nesse sentido que se deve ressaltar o caráter criativamente produtivo do autor e sua resposta total à personagem; o autor não é o agente da vivência espiritual, a sua reação não é um sentimento passivo nem uma percepção receptiva; ele é a única energia ativa e formadora, dada não na consciência psicologicamente agregativa [...] mas em um produto cultural de significação estável, e sua reação ativa é dada na estrutura - que ela mesma condiciona - da visão ativa da personagem como um todo, na estrutura da sua imagem, no ritmo de seu aparecimento, na estrutura da entonação e na escolha dos elementos semânticos [...] (BAKHTIN, 2011, p. 6).

Como reforça o autor, o escritor - agente criador - reflete a respeito de sua personagem e estabelece seus problemas, defeitos, qualidades e a forma como estes serão desenvolvidos no texto. Todavia, tudo isso é vivenciado de fora, pois não são os problemas ou sentimentos do autor, mas de sua personagem. Não se trata de um processo psicológico consciente de transposição de sentimentos internos do criador para o ser criado; ao contrário, o ato da criação da personagem constitui um trabalho estético e consciente.

Não obstante, Bakhtin (2011) não refuta a possibilidade de o escritor expressar suas próprias opiniões por meio da personagem. Entretanto, tais concepções devem ser adaptadas ao contexto interno da obra, isto é, a seu universo diegético e às características da personagem criada. Assim, o discurso passa a não ser diretamente do autor, mas da própria personagem e, se isso for feito de outra maneira, se o discurso do autor for reproduzido de forma destoante da personalidade criada para o ser fictício, o resultado incorre na não coerência interna $e$, por conseguinte, não há relação produtiva entre leitor e obra. Portanto, a personagem é elaborada tendo em vista um contexto específico, i.e., o texto, deve este estar em conformidade com os elementos estéticos desse meio, ou seja, com sua verossimilhança interna (BRAIT, 2006).

Como podemos observar, todo o processo é produzido na mente criativa do escritor, não estando preso a modelos iniciais, mas constituindo a personagem de fora para dentro. Em outras palavras, o escritor concebe a personagem a partir do trabalho intelectual criativo, desenvolvendo um ser 
original passível de ser contemplado em sua totalidade interna e externa. Nesse sentido, autor e personagem são, pois, seres distintos, constituindo o que E. M. Forster (2004) denomina de Homo Sapiens e Homo Fictus: aquele em referência ao sujeito social, autor, leitor; este, em alusão ao ser formado de palavras.

Portanto, consideramos que, ao elaborar Nick Carraway, Fitzgerald o fez partindo da observação e da leitura de seu próprio mundo. Dessa maneira, o autor insere referências externas que remetem aos costumes, ao comportamento das pessoas, bem como aos valores socioculturais em vigor na época. Para tanto, a história é contada do ponto de vista do referido personagem, um sujeito que não pertence àquele mundo, um sujeito de fronteira, que ressignifica aquelas relações para o leitor. É por meio da voz de Nick Carraway que Fitzgerald engendra crítica e revela valores socioculturais de sua época que ainda reverberam na contemporaneidade.

\section{Nick como sujeito de fronteira}

The Great Gatsby é um romance modernista, também considerado um romance da Era do Jazz, de acordo com o próprio autor, F. Scott Fitzgerald (HIGH, 2000). Sua primeira edição foi lançada pela editora Charles Scribner's Sons, em 1925, nos EUA e na França. A história se passa entre duas cidades, Long Island e Nova York, durante o verão de 1922, sendo sua narrativa desenvolvida em primeira pessoa, contada por Nick Carraway, como mencionado anteriormente.

Além do personagem narrador, há o protagonista Jay Gatsby e os demais personagens centrais: Daisy Buchanan, uma garota rica e fútil, objeto da paixão de Gatsby; Tom Buchanan, esposo de Daisy, homem de família tradicional e abastada, com temperamento intempestivo e comportamento inconsequente; Jordan Baker, amiga de Daisy, uma famosa jogadora de golfe que tem um breve romance com Nick; Myrtle Wilson, uma mulher casada, mas possui um romance secreto com Tom, pois é insatisfeita com a vida que leva; George Wilson, esposo de Myrtle, um homem ingênuo, cujo trabalho como mecânico o coloca na base das relações sociais referenciadas no romance; 
Meyer Wolfsheim, amigo e parceiro de negócios de Gatsby, um homem de comportamento reservado e com um passado obscuro.

A história começa quando o jovem Nick Carraway, vindo do estado de Minnesota, considerada uma área rural no período, migra para o estado de Nova York durante o verão do ano de 1922 a fim de estudar negócios. Assim, o personagem se estabelece no distrito chamado de West Egg, na cidade de Long Island. Nessa região, moram famílias de classe média alta, muitas das quais acumularam sua riqueza em décadas recentes. Entretanto, Nick não possui grande fortuna, e sua casa é pequena e simples em relação às propriedades de seus vizinhos. Porém, ele possui graduação em nível superior e conexões com os moradores da região oposta, ou seja, East Egg. Trata-se de uma área habitada por famílias ricas e tradicionais. Sua conexão é com a família Buchanan, mais especificamente, com sua prima, Daisy Buchanan.

Jay Gatsby, embora 'novo rico', é vizinho de Nick, mas mora em uma mansão que sugere estilo gótico e é conhecido por promover festas opulentas. Ao saber do parentesco de Nick com Daisy, Gatsby o convida para uma de suas festas com o intuito de se aproximar do jovem. $\mathrm{Na}$ festa, os dois conversam e o anfitrião pede a Nick que convide Daisy para um encontro em sua própria casa. Depois de relutar, o narrador concorda. Assim, alguns dias depois, Daisy e Gatsby se veem, conversam e sua relação é revelada ao leitor. Os dois, durante o período da Primeira Guerra Mundial, se apaixonaram e tiveram um breve romance. Porém, Gatsby, como soldado, teve que ir para Europa; sozinha, Daisy se casa com Tom, homem abastado. Posteriormente, devido a negócios escusos com Meyer Wolfsheim (apesar da natureza dessas relações nunca ficar esclarecida no romance), Gatsby consegue uma grande fortuna que, consequentemente, eleva seu status social. A partir de então, o personagem passa a nutrir esperanças de que sua ex-namorada abandone 0 casamento com Tom e passe a morar com ele.

Nesse ínterim, Nick e Jordan se envolvem amorosamente e, devido às relações de Jordan na alta sociedade, Nick descobre mais informações a respeito do mundo das pessoas abastadas. Dessa forma, é primeiramente por meio de Jordan que Nick toma conhecimento de um romance extraconjugal de Tom. Todavia, em pouco tempo, o próprio Tom revela seu affair e leva Nick para Nova York, onde costuma e se encontrar com Myrtle. Entretanto, a 
relação dos dois é conflituosa; em uma noite de festa e bebedeira, Tom agride Myrtle, quebrando seu nariz após uma discussão. Em razão disso, os dois separam-se brevemente.

No que diz respeito à relação entre Gatsby e Daisy, o jovem pressiona a moça para que ela revele seu romance e peça divórcio a Tom. Depois de algum tempo, Tom, Gatsby, Jordan e Nick se reúnem numa tarde e viajam para Nova York, onde Dayse é forçada por seu amante a contar a Tom que não o ama - o que não logra em fazê-lo. Como consequência, Gatsby e Tom discutem e, durante o conflito, Tom alega saber a origem da fortuna de Gatsby, afirmando que jovem é um traficante de bebidas. Apesar das acusações serem refutadas, Daisy não se convence e fica confusa. Ainda assim, todos resolvem retornar a East Egg, mas Daisy pede para ir com Gatsby.

Enquanto isso, Myrtle e seu esposo, Wilson, também discutem. Ele a prende num quarto, pois suspeita que ela tenha um romance com outro homem. No entanto, Myrtle consegue escapar, indo em direção a uma rodovia próxima de sua casa. Ao avistar um carro amarelo, ela entra em desespero e, achando que Tom é o motorista, corre em direção ao veículo. Entretanto, o carro segue em alta velocidade, não para e atropela Myrtle, matando-a imediatamente. Wilson presencia a cena e, após se restabelecer, tenta descobrir quem dirigia o veículo. A primeira informação que tem é que o transporte pertenceria a Tom. Contudo, ao interrogar Tom, este acaba revelando que o carro era de Gatsby.

Na mesma noite do acidente, numa conversa entre Gatsby e Nick, este toma conhecimento de que a pessoa que dirigia o carro era Daisy. Assim, ela fora a culpada pela morte de Myrtle. Entretanto, Gatsby escondeu essa informação, assumindo a responsabilidade e escondendo o carro. Não obstante, Wilson procura Gatsby e, na manhã seguinte ao acidente, ele o mata com um tiro pelas costas e, logo após, comete suicídio.

A história termina com o funeral de Gatsby, no qual os únicos que comparecem são Nick, o pai de Gatsby e uma figura misteriosa, que costumava frequentar as festas promovidas em sua mansão. Daisy e Tom viajam para Europa, Nick e Jordan se separam, e ele volta para sua cidade natal. 
Como dissemos anteriormente, todos esses acontecimentos são narrados a partir do ponto de vista de Nick Carraway. A primeira indicação que temos de sua posição periférica e, portanto, oriundo de outra realidade, é por meio de suas considerações a respeito do novo lugar onde irá residir. Vejamos a seguir:

Foi simplesmente obra do acaso que eu tivesse alugado uma casa em uma das comunidades mais estranhas da América do Norte. Ficava naquela ilha estreita e barulhenta que se localiza justamente a leste de Nova York... e na qual existem, entre outras curiosidades da natureza, duas formações geológicas bastante incomuns. A uns trinta quilômetros da cidade, erguese um par de enormes ovos de pedra, idênticos em contorno e separados somente por uma baía estreita, que se projetam para o alto junto à massa de água salgada mais mansa $e$ tranquila do hemisfério ocidental, o grande caminho úmido conhecido como o Estreito de Long Island (FITZGERALD, 2011, p.06) ${ }^{8}$.

Neste fragmento, a condição de não pertencimento de Nick é evidenciada quando o jovem descreve o lugar e revela seu estranhamento em relação ao ambiente. Sua posição marginal, isto é, fronteiriça em relação ao novo lugar e ao novo contexto onde se encontra é enfatizada, o que o coloca na margem dessa nova realidade que está para ser explorada, processada, entendida e ressignificada para o leitor.

Outro momento em que se revela sua posição de fronteira e apresenta uma leitura do ambiente e cultura do período se dá quando o jovem descreve uma das festas de Gatsby. Assim:

Tinha música na casa de meu vizinho todas as noites do verão. Em seus jardins, azulados pela luz da lua, homens e garotas iam e vinham como mariposas por entre os murmúrios, o champanhe e as estrelas. Na maré alta da tarde eu contemplava seus hóspedes mergulhando da torre de seu ancoradouro flutuante ou tomando banhos de sol na areia quente do seu trecho de praia, enquanto seus dois barcos a motor cortavam as águas do Estreito, puxando esquiadores sobre cataratas de espuma. Nos finais de semana, seu RollsRoy virava um ônibus, conduzindo grupos de e para a cidade

\footnotetext{
${ }^{8}$ Os fragmentos apresentados em português são da tradução de William Lagos.

${ }^{9}$ Texto no original: "It was a matter of chance that I should have rented a house in one of the strangest communities in North America. It was on that slender riotous island which extends itself due east of New York - and where there are, among other natural curiosities, two unusual formations of land. Twenty miles from the city a pair of enormous eggs, identical in contour and separated only by a courtesy bay, jut out into the most domesticated body of salt water in the Western hemisphere, the great wet barnyard of Long Island Sound".
} 
desde as nove da manhã até muitas horas depois da meianoite [...]. E, nas segundas-feiras, oito criados, inclusive um auxiliar de jardineiro contratado só para esses dias, trabalhavam o dia todo com esfregões, ancinhos, martelos e tesouras de podar, reparando os estragos da noite anterior (FITZGERALD, 2011, p. 30; grifos meus) ${ }^{10}$.

Além do momento de prosperidade pelo qual os EUA passavam, o comportamento de um determinado grupo social privilegiado e a forma como suas relações estavam estruturadas se mostram de maneira excessiva. É importante perceber, por exemplo, quando o personagem afirma que os homens e garotas se comportavam como mariposas. A palavra empregada em inglês é girls em contradição com men, mas não women. Isso denota, primeiramente, uma relação entre os gêneros - importante ressaltar a sugestão de que homens mais velhos procuravam a companhia de jovens moças, provavelmente, atraídas (como as mariposas são atraídas pela luz) por sua riqueza e poder. Outro ponto relevante é quando o personagem menciona o número de empregados e suas funções na mansão de Gatsby. Essa assertiva indica mais um elemento social, a divisão de classes; isto é, revela uma incongruência na ideia do sonho americano, que não é para todos, pois para que as pessoas abastadas vivam de maneira hedonista, outros terão que Ihes servir.

Essa ideia de distinção de classes também é evidenciada pela descrição da mansão de Tom e Daisy, por Nick, quando ele os visita:

A casa deles era ainda mais imponente do que eu esperava, uma mansão em estilo georgiano colonial, construída junto à baía, pintada em tons alegres de vermelho e branco. O gramado começava na praia e subia uns quatrocentos metros até a porta da frente, intercalado por relógios de sol, pequenos muros de tijolos e canteiros de flores resplandecentes. [...] A fachada da casa era quebrada por uma série de portas-janelas envidraçadas de cima a baixo, em estilo francês, brilhantes ao reflexo dourado do sol e totalmente abertas para receber a brisa cálida da tarde. Tom Buchanan, vestido em roupas de

\footnotetext{
${ }^{10}$ Texto no original: "There was music from my neighbor's house through the summer nights. In his blue gardens men and girls came and went like moths among the whisperings and the champagne and the stars. At high tide in the afternoon I watched his guests diving from the tower of his raft, or taking the sun on the hot sand of his beach while his two motorboats slit the waters of the Sound, drawing aquaplanes over cataracts of foam. On weekends his Rolls-Royce became an omnibus, bearing parties to and from the city between nine in the morning and long past midnight [...]. And on Mondays eight servants, including an extra gardener, toiled all day with mops and scrubbing-brushes and hammers and garden-shears, repairing the ravages of the night before".
} 
montaria, estava de pé, em frente ao pórtico de entrada, com as pernas bem afastadas uma da outra (FITZGERALD, 2011, p. 07$)^{11}$.

Nesse sentido, a posição periférica de Nick é, novamente, reforçada. O jovem descreve a mansão de uma maneira quase onírica, como alguém não acostumado àquela atmosfera, alguém que está deslumbrando, e enumera várias características que indicam a posição social superior de Tom e Daisy. Há elementos estrangeiros, como janelas francesas. Nick também diz que a mansão é em estilo georgiano, indicando a sofisticação do casal e seu poder financeiro. Dessa forma, enquanto em East Egg se localizam as famílias ricas tradicionais, mais aristocráticas, representadas pelo casal Buchanan, em West Egg, lar de Gatsby, se encontra a classe média alta e os novos ricos, que procuram se adequar ao modelo padrão, ou seja, imitar os que moram do outro lado da baía a fim de se adequar ao estilo de vida da classe social simbolizada pelos Buchanan.

Ao observamos as descrições na voz do personagem Nick, podemos perceber também elementos diversos, que, em seu todo, se configuram num organismo (LÓTMAN, 1996) - neste caso, um organismo estético, mas gerador de significados. Numa conversa com Daisy, a personagem revela a Nick que quando sua filha nasceu ela ficou desapontada. E relata o seguinte:

Bem, ela ainda não tinha uma hora de vida e só Deus sabe onde estava Tom. Eu acordei da anestesia com um sentimento de completo abandono e imediatamente perguntei à enfermeira se era menino ou menina. Ela me disse que era uma menina e então virei meu rosto para o lado e chorei. "Tudo bem," - eu disse - "estou contente que seja uma menina. Espero que seja uma menina boba: é a melhor coisa que pode acontecer a uma menina neste mundo, ser uma linda bobinha" (FITZGERALD, 2011 , p. 15) ${ }^{12}$.

\footnotetext{
${ }^{11}$ Texto no original: "Their house was even more elaborate than I expected, a cheerful red-andwhite Georgian Colonial mansion, overlooking the bay. The lawn started at the beach and ran toward the front door for a quarter of a mile, jumping over sun-dials and brick walks and burning gardens [...]. The front was broken by a line of French windows, glowing now with reflected gold and wide open to the warn windy afternoon, and Tom Buchanan in riding clothes was standing with his legs apart on the front porch".

12 Texto no original: "[...] she was less than an hour old and Tom was God knows where. I woke up out of the ether with an utterly abandoned feeling, and asked the nurse right away if it was a boy or a girl. She told me it was a girl, and so I turned my head away and wept. 'All right', I said, 'I'm glad it's a girl. And I hope she'll be a fool - that's the best thing a girl can be in this world, a beautiful little fool".
} 
Dessa forma, ao narrar esse episódio de sua vida para Nick, um homem que não pertence ao mesmo mundo dela, Daisy o faz também para o leitor. Trata-se da revelação de um sistema opressor em relação ao gênero feminino, onde, apesar de algumas mudanças socioculturais ocorridas no período, como maior liberdade sexual, a mulher ainda ocupava um lugar social e cultural inferior ao do homem. Em outro momento, num diálogo entre Nick e Gatsby a respeito de Daisy, ocorre o seguinte:

Gatsby voltou-se para mim, tenso:

- Não consigo falar nada dentro da casa dele, meu velho.

- Daisy tem uma voz indiscreta - observei.

- Está cheia de... - hesitei, sem saber como me expressar.

- ...sua voz está cheia de dinheiro - afirmou ele, de repente.

Pois era isso mesmo. Nunca havia entendido antes. Sua voz estava cheia de dinheiro... Era esse o encanto inexaurível que subia e descia enquanto ela mudava de tom, era o tinir de moedas, a canção de um címbalo contida nela. No alto da torre de um palácio branco, a filha do rei, a garota dourada... (FITZGERALD, 2011, p. 88) ${ }^{13}$.

Ao afirmar que a voz de Daisy, seu grande amor, era cheia de dinheiro, Gatsby sugere, sutilmente, que as relações humanas, em seu contexto, são mediadas pelo dinheiro mais do que pela empatia, solidariedade ou respeito ao individuo como figura humana. Novamente, é Nick quem escuta e repassa esse diálogo ao leitor, e é possível que um leitor do século $X X I$ repense sua própria realidade e as relações socioculturais hodiernas. Nesse sentido, o personagem de ficção, ainda que sendo um homus fictus (FROSTER, 2011), assume uma função crítica, como discutido por Bakhtin (2011), na narrativa de Fitzgerald.

Além disso, Nick, por ocupar uma posição fronteiriça abstrata, sugere, no mundo diegético da narrativa de Fitzgerald, a ocorrência de transformações entre os elementos de uma semiosfera e de outra, isto é, entre diferentes grupos socioculturais. Desse modo, ao revelar o caso extraconjungal de Tom Buchaman com Myrtle Wilson e descrever o apartamento onde os encontros ocorrem, o personagem expõe um novo ambiente, com um sentido peculiar:

\footnotetext{
${ }^{13}$ Texto no original: "Gatsby turned to me rigidly: - 'I can't say anything in this house, old sport.' 'She's got an indiscreet voice,' I remarked. 'It's full of -'I hesitated. - 'Her voice is full of money.' He said suddenly. That was it. l'd never understood before. It was full of Money - that was the inexhaustable charm that rose and fell in it, the jingle of, the cymbal's song of it...high in a white palace the king's daughter, the golden girl..."
} 
O apartamento ficava no último andar - uma pequena sala de estar, uma pequena sala de jantar, um pequeno quarto e um banheiro. A sala de estar estava atulhada de móveis estofados com um tecido que parecia uma tapeçaria, grandes demais para o local, de modo que, ao movimentar-se pela peça, as pessoas tropeçavam continuamente em cenas de damas passeando pelos jardins de Versalhes. O único quadro que havia nas paredes era uma fotografia superampliada, aparentemente de uma galinha sentada em uma pedra fora de foco. [...]. Diversos exemplares antigos de Town Tattle estavam sobre a mesa, juntamente com um livro intitulado Simão, chamado Pedro e algumas revistinhas de escândalos da Broadway (FITZGERALD, 2011, p. 23) ${ }^{14}$.

Um apartamento na cidade, porém, não no centro; um ambiente que reúne elementos que remetem à classe social de Tom, mas que conserva características da classe social de Myrtle, bem como de suas identidades. A maneira como apartamento é descrito, isto é, os móveis, a tapeçaria, os quadros, o próprio espaço onde o imóvel é localizado, tudo isso denota uma mistura de elementos das classes sociais dos dois personagens envolvidos, de modo que há dialogismo e ressignificação de valores que, afinal, revela outra classe social e outros comportamentos, ou seja, outra semiosfera. E, assim sendo, Nick age como um filtro tradutor (LÓTMAN, 1996) para o leitor, uma vez que é a voz do personagem que descreve e conta os eventos que ali ocorrem.

Outro momento em que o diálogo entre determinados grupos socioculturais é apresentado ao leitor se dá quando Nick e Gatsby viajam para visitar Wolfsheim e escutam a história de um homem que foi assassinado:

- O velho Metrópole - lamentou-se o triste sr. Wolfsheim. Cheio de rostos mortos e perdidos. Cheio de amigos que partiram para sempre. Não poderei esquecer, não enquanto viver, a noite em que mataram Rosy Rosenthal lá em frente. Estávamos nós seis sentados à mesa, e Rosy tinha comido e bebido muito a noite toda. Já era quase de manhã quando o garçom aproximou-se dele com uma expressão muito estranha e disse que havia uma pessoa que queria falar-Ihe em frente ao restaurante.

$[\ldots]$

\footnotetext{
${ }^{14}$ Texto no original: "The apartment was on the top floor - a small living room, a small diningroom, a small bedroom, and a bath. The living-room was crowded to the doors with a set of tapestrie furniture entirely too large for it, so that to move about was to stamble continually over scenes of ladies swinging in the gardens of Versailles. The only picture was an overenlarged photograph, apparently a hen sitting on a blurred rock. [...] Several old copies of Town Tattle on the table together with a copy of Simon Called Peter, and some of the small scandal magazines of Broadway".
} 
Então ele foi até a calçada e os caras acertaram três tiros direto naquela barriga cheia e fugiram em um automóvel que estava esperando (FITZGERALD, 2011, p. 52) ${ }^{15}$.

Portanto, ao apresentar personagens distinguidos claramente por suas classes sociais e em diferentes ambientes, Nick revela o diálogo entre diferentes esferas socioculturais, de modo que apresenta um organismo e seus diferentes componentes que o estruturam, tal qual uma semiosfera, como alude Lótman (1996). Dessa maneira, há sistemas que interagem e, consequentemente, ocorrem transformações de valores que podem ser representados pelos comportamentos dos personagens, bem como pelo ambiente em que ocupam, como a mansão dos Buchanan, o apartamento de Myrtle, o restaurante onde Gatsby, Wolfsheim e o próprio Nick conversam.

Entretanto, o valor central das semiosferas do romance é o dinheiro; é esse elemento que está presente no desejo, na vida e na morte dos personagens. É em torno da ideia de sucesso e poder simbolizados pela riqueza, pelo dinheiro, que as dinâmicas e transformações sociais são apresentadas ao leitor. Nesse sentido, Nick, por estar na fronteira de todos esses ambientes, por sua condição de um ser de fronteira, atua como um tipo de filtro tradutor, pois é através de seu ponto de vista que essas dinâmicas e os problemas sociais, morais, econômicos são revelados.

\section{Considerações finais}

A obra de F. Scott Fitzgerald apresenta a dinâmica sociocultural das décadas de 1920, como mencionado anteriormente. Ao tratar do assunto, Bryant Magnun (2013) afirma que a produção do autor pode ser considerada uma expressiva e perspicaz crônica da Era do Jazz e também da Grande Depressão, uma vez que engloba elementos históricos, sociais e culturais

\footnotetext{
${ }^{15}$ Texto no original: "'The old Metropole', brooded Mr Wolfsheim gloomily. 'Filled with faces dead and gone. Filled with friends gone now forever. I can't forget sol ong as I live the night they shot Rosy Rosenthal there.it was six o fus at the tanble, and Rosy had eat and drunk a lot all evening. When it was almost morning the waiter came up to him with a funny look and says somebody wants to speak to him outside. [...] Then he went out on the sidewalk, and they shot him three times in his full belly and drove away".
} 
daquele período. Portanto, reforçamos a ideia da representação de uma semiosfera, de acordo com os estudos de Lótman (1996).

Não obstante, Fitzgerald ganhou maior notoriedade apenas após a publicação de The Great Gatsby em 1925. A partir de então, o autor tornou-se uma celebridade e passou a receber críticas diversas. Desse modo, algumas mencionavam seu talento, mas outras consideravam suas obras como produções sem profundidade artística, apesar de reconhecerem o potencial criativo do autor (BRYER, 2013). Além disso, outro fator relevante é que seu trabalho era considerado, de modo geral, como sendo baseado direta e unicamente em suas experiências pessoais (CURNNUT, 2007), o que corroborava a ideia de superficialidade, pois Fitzgerald também levava, no auge de sua carreira, uma vida hedonista.

Contudo, a partir da década de 1970, sua obra passou a ser objeto de estudos mais substanciais que consideravam seu contexto de produção e debruçavam-se sobre questões estéticas e políticas (PRIGOZY, 2013). Desde então, Fitzgerald ocupa lugar de destaque no cânone literário estadunidense. A esse respeito, Ruth Prigozy (2013, p. 80) afirma que o jornal The New York Times elegeu, no ano 2000, a obra The Great Gatsby como um dos mais importantes romances do século XX, ficando atrás apenas de Ulysses, publicado em 1922, do escritor irlandês James Joyce.

As questões socioculturais apresentadas no romance de Fitzgerald não se limitam à sua própria época, se considerarmos que a literatura transcende seu contexto de produção e revela as segmentações culturais e políticas de uma sociedade, uma vez que, em sua condição de arte, isto é, como produto estético, têm capacidade para tal (TARAS, 2013). Portanto, é correto afirmar que a literatura nos ajuda a compreender as diversas realidades socioculturais e históricas. Por essa razão, se pensarmos nos sujeitos que não produzem de acordo com parâmetros estabelecidos, que não obedecem às normas de comportamento, que não se identificam com manifestações culturais dominantes, que estão fora do centro de um organismo (LÓTMAN, 1996), esses sujeitos podem ser considerados seres de fronteira.

Entretanto, são seres que acabam traduzindo elementos e transformando as relações e os significados sociais, culturais e históricos. $\mathrm{Na}$ contemporaneidade, podemos citar, como exemplo, a situação dos imigrantes 
mexicanos que cruzam as fronteiras com os EUA. Essas pessoas procuram integrar uma semiosfera e se adequar a ela; contudo, os que conseguem transpor essa fronteira física ainda têm que lidar com as fronteiras abstratas (LÓTMAN, 1996), como questões culturais, comportamentais, linguísticas, políticas etc. Dessa maneira, esses seres acabam filtrando, traduzindo, ressignificando e transformando, dentro de um espaço físico e cultural, determinados elementos em um organismo maior. Como consequência, há formação de novos grupos socioculturais que interagem com os grupos dominantes de um sistema. Trata-se de relações dialógicas, como mencionado anteriormente, mas também conflituosas. Essas relações entre seres de fronteira e o centro de uma semiosfera podem ser percebidas na situação dos refugiados na América e na Europa e na própria proposta do Presidente estadunidense, Donald Trump, de construir um muro para separar o México dos Estados Unidos, por exemplo. Todas essas ocorrências podem ser relacionadas ao romance que constitui o corpus deste trabalho.

Seres de fronteira, além de transformarem, dinamizam as relações culturais, revelam contradições e questionam paradigmas e valores socioculturais e históricos, tal qual ocorre com o personagem Nick Carraway no romance The Great Gatsby (2016). É através de um ser de fronteira que se apresentam as incongruências de um grupo social dominante, de uma semiosfera e se tem um panorama dos elementos ideológicos e culturais que compõem os valores e o comportamento de uma classe social que simboliza a ideia de progresso, equilíbrio e felicidade, mas que é excludente, desigual e inconsequente - características apresentadas, reforçamos, através da voz do personagem supracitado.

Nick Carraway, como um ser de fronteira, ou seja, por sua posição periférica em relação aos demais personagens centrais do romance, e também por sua característica estética (BAKHTIN, 2011), quer dizer, por se tratar de um personagem de ficção, atua como um sujeito ressignificador entre uma semiosfera representada na obra The Great Gatsby (2016), de F. Scoott Fitzgerald, e o leitor contemporâneo, suscitando reflexões a respeito das próprias relações sociais e culturais hodiernas. Dessa forma, a partir de seus relatos e de diálogos com outros personagens, o leitor pode ser levado a refletir acerca das relações apresentadas no romance em seu próprio contexto 
sociocultural, assim, também reconhecendo idiossincrasias, criticando e conjeturando a respeito de determinados valores culturais e sociais de seu próprio tempo.

\section{Referências}

BAKHTIN, M. O autor e a personagem na atividade estética. In: Estética da criação verbal. Tradução de Paulo Bezerra. São Paulo: $\overline{\text { Martins }}$ Fontes, 2011.p.1-192.

BRAIT, B. A personagem. São Paulo: Ática, 2006.

BRYER, R. Jackson. Contemporary critical reception. In: MAGNUN, B. (Ed.). F. Scott Fitzgerald in Context. Cambridge: Cambridge University Press, 2013. p. $66-77$.

CURNNUT, K. The Cambridge Introduction of F. Scott Fitzgerald. Cambridge: Cambridge University Press, 2007.

FITZGERALD, F. Scott. The Great Gatsby. London: Arcturus Holdings Limited, 2016. 2011.

O grande Gatsby. Trad. William Lagos. Porto Alegre: L\&PM Pocket,

FORSTER, E. Aspectos do romance. Trad. Sergio Alcides. São Paulo: Globo, 2004.

HIGH, P. An Outline of American Literature. New York, NY: Longman Inc., 2000.

LÓTMAN, I. La semiosfera I: semiótica de la cultura e del texto. Trad. Desiderio Navarro. Valência: Frónensis Cátedra, 1996.

MAGNUN, B. (Ed.). F. Scott Fitzgerald in Context. Cambridge: Cambridge University Press, 2013.

PRIGOZY, R. The Fitzgerald Revival. In: MAGNUN, B. (Ed.). F. Scott Fitzgerald in Context. Cambridge: Cambridge University Press, 2013. p. 78 87.

ROSENFELD, A. Literatura e personagem. In: CANDIDO, A. et al. A personagem de ficção. São Paulo: Perspectiva, 2011. 
TARAS, R. Why we need the novel: understanding world politics through literature. The fletcher forum of world affairs, New Orleans, USA, v.37, n.2, p. 185 - 195, 2013. Disponível em: <https://static1.squarespace.com/static/ 579fc2ad725e253a86230610/t/57ec7c09be6594808a456770/1475116048546/ Taras-37-2.pdf>. Acesso em: 15 dez. 2018. 